\title{
Child and adolescent psychiatry-a model for medical teaching
}

\author{
Derek Steinberg MPhil DPM
}

J R Soc Med 2004;97:545-546

You would not expect to find child and adolescent psychiatry, the province of a modest number of clinicians, on the curriculum of many doctors other than child and adolescent psychiatrists. And yet the way that we need to approach our work in child psychiatry (I will call it this for short) could be a model for the medicine of the future, both as a general philosophy and in the clinical detail.

In a sense the future is already here. Take such varied issues as patient autonomy, choice and consent; the place of high-tech new treatments and methods of investigation and the roles of counselling, psychotherapy, drug treatments, alternative therapies and of course no treatment at all; options such as contraception, termination, fertilization, euthanasia and gene therapy; matters of compulsory treatment, who should and should not look after children, personality disorder in relation to crime, self-harm, suicide and 'life-style' disorders; an ever-growing list of syndromes of uncertain nature, aetiology and treatment; and the different subcultural attitudes to health and treatment, in which I would include the autonomy and leadership of the doctor in multidisciplinary work. Of all this, four things can be said. First, each of these areas can generate dilemmas on which several High Court judges and a whole clutch of moral philosophers, expert witnesses and clerics could reach nothing better than an arbitrary conclusion if they had their heads together for a year. Second, almost every person, professional or lay, has a clear opinion to assert on each of these issues while consensus is entirely lacking. Third, the obvious trend is for such dilemmas to increase rather than decrease; yet fourth, in ordinary day-to-day work doctors are expected to make decisions on all these things by themselves and sometimes at high speed - what Leon Eisenberg ${ }^{1}$ described as having to act amidst ambiguity. With respect to point four, the child psychiatric clinic stands out in that hardly a day passes without one or more of the above kinds of matters coming up-not peripherally, as if they might just go away if ignored, but right in the centre of the frame, complete with family members in conflict and fellow healthcare workers in greater or lesser degrees of disagreement. Moreover, quite a bit of brand new (at least to you) and supposedly crucially relevant material is coming through on the internet 24

High Cliff House, Lyme Regis DT7 3EQ, UK hours a day. I will not say that child psychiatrists take all this in their stride, but they do take it in their stagger. In particular, we have to act with the authority and informed consent of the parent if not the adolescent child, and both may be ambivalent; whatever one's instinctive feel for 'patient-empowerment' Salmon and Hall $^{2}$ among others have shown that the issues are by no means clear-cut, and that what starts out as autonomy can end as the reverse.

Now, doctors in general do not enjoy sharing control with other professionals, still less with their clientele, although those drawn to child psychiatry may well be more open to such ways of operating. The following aspects of work in the subspecialty, however, are integral: first, most diagnoses, from trivial aberrations to the most serious and life-threatening conditions, are open to dispute; second, it was child psychiatry that introduced the notion of multidimensional assessment and development into conceptions of disorder (namely that disorders and the physical, psychological and social characteristics of the patient interact with time and maturation); third, it is not possible to make a useful assessment without knowing, at the very least, what parents and schoolteachers report, supplemented by the findings and perspectives of other experts such as the family doctor, psychologists and social workers past and present; and fourth, it is not feasible to manage a treatment plan without the consent and active collaboration of several people from this list together with that of the child, whose legal autonomy will vary with his or her age and the nature of the disorder. By which I mean, for example, that if a 15year-old girl with anorexia nervosa will not take part in family therapy (one of the established treatments) or admission to hospital (another) then you have a new problem - or as the optimists among us say, a new focus for work. ${ }^{3}$ After much heart-searching and debate, you may find that a mother is willing and able to give methylphenidate to her child with attention-deficit hyperactivity disorder, only for the natural father and her present partner to voice different opinions backed by internet printouts and newspaper cuttings, not to mention lawyers.

The point is that multidimensional, multidisciplinary, holistic, patient-centred, family-focused care, with extensive consultation on all sides, is the only practical way for child psychiatrists, to work. And it seems very likely that general medicine is going the same way. ${ }^{4}$ 
The good news is that child psychiatry, through a combination of inclination, theories and necessity, has evolved ways of coping; and, not for the first time in the present age, it is the children - part grown up and part childish, part independent and assertive, part dependent and helpless - who are forcing the pace. They and their advocates are not inhibited about highlighting the flaws in what adults do. As Donald Winnicott pointed out in respect of challenges from the adolescent, we do not have to go along with them, but we do have to find ways to respond. ${ }^{5}$ If students of medicine had a chance, in their curriculum, to see how we go about the practical details of assessment and treatment planning in child psychiatry, they might find the experience useful for professional life as it is now emerging.

\section{REFERENCES}

1 Eisenberg L. The ethics of intervention: acting amidst ambiguity. J Child Psychol Psychiatry 1975;16:93-104

2 Salmon P, Hall G. Patient empowerment or the emperor's new clothes? $J$ R Soc Med 2004;97:53-6

3 Steinberg D. Letters from the Clinic. London: Brunner Routledge, 2000

4 Steinberg D. Consultation, Complexity and the Other Side of Medical Care. Abingdon: Radcliffe, 2005

5 Winnicott DW. Playing and Reality. London: Tavistock 1971 